\title{
A toponímia de comunidades quilombolas do Centro-Oeste: relações entre língua, cultura e história nas formas de nomeação
}

The toponymy of Quilombola communities in the Midwest: relations between language, culture and history in the forms of appointment

\author{
Nagila Kelli Prado Sana Utinói ${ }^{1}$ \\ Aparecida Negri Isquerdo ${ }^{1}$
}

DOI: http://dx.doi.org/10.20435/tellus.vi44.752

\begin{abstract}
Resumo: Este artigo tem como propósito discutir questões históricas, sociais e ideológicas relacionadas às nomeações de comunidades quilombolas, situadas na região Centro-Oeste, devidamente certificadas pelo IBGE (Instituto Brasileiro de Geografia e Estatística) até 2016. O estudo pauta-se na análise toponímica das denominações das 131 comunidades quilombolas que compõem o corpus deste estudo que, por sua vez, reuniu 131 topônimos, assim distribuídos: Mato Grosso (78); Goiás (32); Mato Grosso do Sul (21). Busca-se examinar em que proporção os topônimos que nomeiam essas comunidades refletem aspectos linguísticos, históricos, culturais relacionados aos povos africanos no Brasil. Para tanto, toma-se como parâmetro o referencial teórico Dick (1990; 1992; 1998; 2008) para a análise dos topônimos; as contribuições de Castro (2001; 2003); de Petter (2004) e de Petter e Cunha (2015) para a análise da questão da presença de línguas africanas no léxico do português do Brasil. Em termos linguísticos, dos topônimos analisados, 2,96 \% são de base africana; 6,10\% são de origem indígena e 90,94\% provêm da língua portuguesa e/ou de outras línguas europeias. Dentre as línguas africanas representadas no recorte de topônimos estudados, destacam-se as línguas kwa (Exu), kikongo Kimbundu (Monjolo; Kalunga). No que se refere à natureza dos nomes, predominam topônimos de natureza antropocultural com destaque para os sociotopônimos (Família Bispo; Família Jarcem) e os hagiotopônimos (Santo Antônio; São João Batista). Os de natureza física predominam os geomorfotopônimos seguido dos fitotopônimos. A predominância de nomes de santos do hagiológico romano que têm seus correspondentes nos cultos africanos apontam para a história do afro-brasileiro e seu ideário. Em síntese, o estudo demonstra a importância
\end{abstract}

1 Universidade Federal do Mato Grosso do Sul (UFMS), Três Lagoas, Mato Grosso do Sul, Brasil. 
dos topônimos como marcadores ideológicos, pois por meio da toponímia pode-se recuperar aspectos culturais, no caso, indícios do modus vivendi do povo africano em território brasileiro e a questão da valorização das línguas africanas no léxico e por extensão, na toponímia.

Palavras-chave: toponímia; história, cultura, ideologia.

\begin{abstract}
This article aims to discuss historical, social and ideological issues related to the nominations of quilombola communities, located in the Midwest region, duly certified by IBGE (Brazilian Institute of Geography and Statistics) until 2016. The study is based on the toponymic analysis of denominations of the 131 quilombola communities that make up the corpus of this study, which in turn brought together 131 toponyms, distributed as follows: Mato Grosso (78); Goiás (32); Mato Grosso do Sul (21). It seeks to examine to what extent the toponyms that name these communities reflect linguistic, historical, cultural aspects related to the African peoples in Brazil. For this purpose, the theoretical framework Dick (1990; 1992; 1998; 2008) for the analysis of toponyms; the contributions of Castro (2001; 2003); Petter (2004) and Petter and Cunha (2015) for the analysis of the question of the presence of African languages in the Brazilian Portuguese lexicon. In linguistic terms, of the toponyms analyzed, $2.96 \%$ are African-based; $6.10 \%$ are of indigenous origin and $90.94 \%$ are from Portuguese and /or other European languages. Among the African languages represented in the study of toponyms studied, the languages of Kwa (Exu), Kikongo Kimbundu (Monjolo; Kalunga) stand out. With regard to the nature of names, toponyms of an anthropocultural nature predominate, with emphasis on sociotoponyms (Família Bispo; Família Jarcem) and hagiotoponyms (Santo Antônio; São João Batista). Those of a physical nature predominate the geomorphopoponyms followed by the phytotoponyms. The predominance of the names of saints from the Romanogic hagiology have their counterparts in African cults point to the history of Afro-Brazilians and their ideas. In summary, the study demonstrates the importance of place names as ideological markers, because through toponymy, cultural aspects can be recovered, in this case, evidence of the modus vivendi of the African people in Brazilian territory and the question of the valorization of African languages in the lexicon and by extension, in toponymy.
\end{abstract}

Keywords: toponymy; history; culture; ideology.

\title{
1 INTRODUÇÃO
}

É perceptível a raridade de trabalhos escritos em língua portuguesa ou realizados por pesquisadores portugueses e brasileiros sobre topônimos de base africana na toponímia brasileira. Ainda que não tão representativos quanto os da toponímia indígena, os nomes de lugares de base africana podem refletir 
questões linguísticas e ideológicas complexas. Essa lacuna por si só justifica este estudo, cujos resultados podem refletir índices das relações culturais e econômicas historicamente estabelecidas entre África, Brasil e Portugal, sobretudo, a partir da Lei n. 10.639/2003, que tornou obrigatória a inclusão da história africana e da cultura afro-brasileira no currículo da Educação Básica (Ensino Fundamental e Médio).

Estudos toponímicos que tenham como objeto de investigação a influência africana na seleção dos nomes de lugares devem partir de fundamentos da Linguística africana que, por sua vez, conduz à Linguística descritiva que busca descrever como uma língua funciona, em um dado momento da sua história, analisando a sua configuração formal. No caso das línguas africanas, pode contribuir para o conhecimento da história da África e, também, a possibilidade apontada por Childs (2003) de que o continente africano seria onde a espécie humana poderia ter aparecido pela primeira vez.

O conhecimento acerca das línguas africanas é importante para melhor interpretação de situações de contatos linguísticos, da presença de pidgins e de crioulos convivendo com a língua portuguesa, assim como para a compreensão das estruturas das línguas que foram transplantadas para o Brasil durante o período do tráfico de negros como escravos e as suas respectivas contribuições para a formação do léxico do português do Brasil e, por extensão, da toponímia brasileira.

Este artigo tem a pretensão de examinar aspectos da manifestação de línguas africanas na toponímia das 131 comunidades quilombolas pertencentes à região Centro-Oeste do Brasil, certificadas até 2016², buscando identificar manifestações de aspectos desse processo na nomeação dessas comunidades. Buscam-se, pois, respostas sobre possíveis influências das línguas e culturas africanas na toponímia quilombola dos três estados do Centro-Oeste e, por extensão, a presença de indícios de tendências ideológicas na nomeação das comunidades em estudo.

2 Este trabalho discute resultados parciais de uma pesquisa mais ampla em desenvolvimento como projeto de tese de doutorado que tem, como objeto de investigação, a toponímia de comunidades quilombolas situadas nas cinco grandes regiões geográficas do Brasil, certificadas até 2016. 


\section{APONTAMENTOS DE NATUREZA HISTÓRICA}

De acordo com Capucho (2008, p. 257), a partir da segunda metade do século XV, com o início da época das navegações e da fase de expansão portuguesa, o português foi levado, juntamente com os homens, para outras partes do mundo, chegando a África, a Ásia, a América. Os navios carregavam não só pessoas, mas também línguas e cultura(s) que se instalaram nos novos territórios e estabeleceram contatos com populações nativas e com elas tentaram comunicar. Nesse cenário, questões políticas dominantes na época e a permanência dos portugueses nesses territórios proporcionaram situações para que a língua de origem dos colonizadores fosse imposta, originando variados processos de miscigenação e proporcionando um ambiente de pluralidade linguística. A necessidade imediata de estabelecer comunicação favoreceu, num primeiro momento, a formação de pidgins, ou seja, formas de línguas veiculares em contato por necessidades de comunicação entre falantes locais cujas línguas maternas eram tão diversas quanto os espaços geográficos onde se situavam os povos nativos e os portugueses colonizadores.

Assim, no caso do Brasil, ao se reconhecer que as línguas de substrato do português brasileiro são expressões culturais aceita-se a tese de que a presença africana foi marcante na formação da nação brasileira, o que conduz à reflexão acerca da história e da construção de identidade do Brasil. Os dados demográficos da população no século XIX (Quadro 1) demonstram que os portugueses e descendentes constituíam apenas um terço da população no território brasileiro.

Petter e Cunha (2015, p. 222) registram que o tráfico negreiro iniciou no Brasil em 1502 e foi extinto em 1860. Nesse período, segundo as mesmas autoras, vieram para o Brasil, aproximadamente, 3.500.000/3.600.000 africanos. Desta forma, o tráfico de escravos acabou atuando como processo inerente à colonização e à exploração da terra brasileira e, nos anos subsequentes, quando o quantitativo de povos não europeus constituiu a maioria absoluta. O quadro de Alberto Mussa (1991), reproduzido a seguir, traz dados acerca do exposto. 
A toponímia de comunidades quilombolas do Centro-Oeste: relações entre língua, cultura e história nas formas de nomeação

Quadro 1 - Número de africanos, indígenas e europeus no Brasil (séculos XVI a XIX)

\begin{tabular}{|c|c|c|c|c|c|}
\hline & $\mathbf{1 5 3 8 - 1 6 0 0}$ & $\mathbf{1 6 0 1 - 1 7 0 0}$ & $\mathbf{1 7 0 1 - 1 8 0 0}$ & $\mathbf{1 8 0 1 - 1 8 5 0}$ & $\mathbf{1 8 5 1 - 1 8 9 0}$ \\
\hline Africanos & $20 \%$ & $30 \%$ & $20 \%$ & $12 \%$ & $2 \%$ \\
\hline Negros brasileiros & - & $20 \%$ & $21 \%$ & $19 \%$ & $13 \%$ \\
\hline Mulatos & - & $10 \%$ & $19 \%$ & $34 \%$ & $42 \%$ \\
\hline Brancos brasileiros & - & $05 \%$ & $10 \%$ & $17 \%$ & $24 \%$ \\
\hline Europeus & $30 \%$ & $25 \%$ & $22 \%$ & $14 \%$ & $17 \%$ \\
\hline Índios integrados & $50 \%$ & $10 \%$ & $8 \%$ & $4 \%$ & $2 \%$ \\
\hline
\end{tabular}

Fonte: Mussa (1991, p. 163).

Conforme Prandi (2000, p. 52-65), a escravidão teve início no Brasil no século XVI, com o denominado ciclo da Guiné ${ }^{3}$, quando foram trazidos para o novo território os povos, grosso modo, chamado de sudaneses. Na sequência ocorre o ciclo do Congo e Angola, que foi responsável pelo tráfico de negros denominados bantos. E, em meados do século XVIII, o ciclo "Baiano" em que ocorriam as embarcações de escravos na Bahia. Havia certa preferência pelos escravos vindos da região da África da baía do Benim. Já no século XIX, os povos escravos foram trazidos de todas as regiões da África com predominância de Angola e de Moçambique. No século XIX o ciclo da Costa de minas trouxe novamente os sudaneses. As figuras, a seguir, mostram a localização dos principais ciclos econômicos (Figura 1) e as principais rotas do tráfico transatlântico (Figura 2). No século XIX o ciclo da Costa de minas trouxe para o Brasil novamente os sudaneses. 
Figura 1 - Referências territoriais dos principais ciclos econômicos coloniais

\section{BRASIL REFERÊNCIAS TERRITORIAIS DOS PRINCIPAIS CÍCLOS ECONÔMICOS COLONIAIS}

\section{Geog. Rafael Sanzio Araújo dos Anjos}

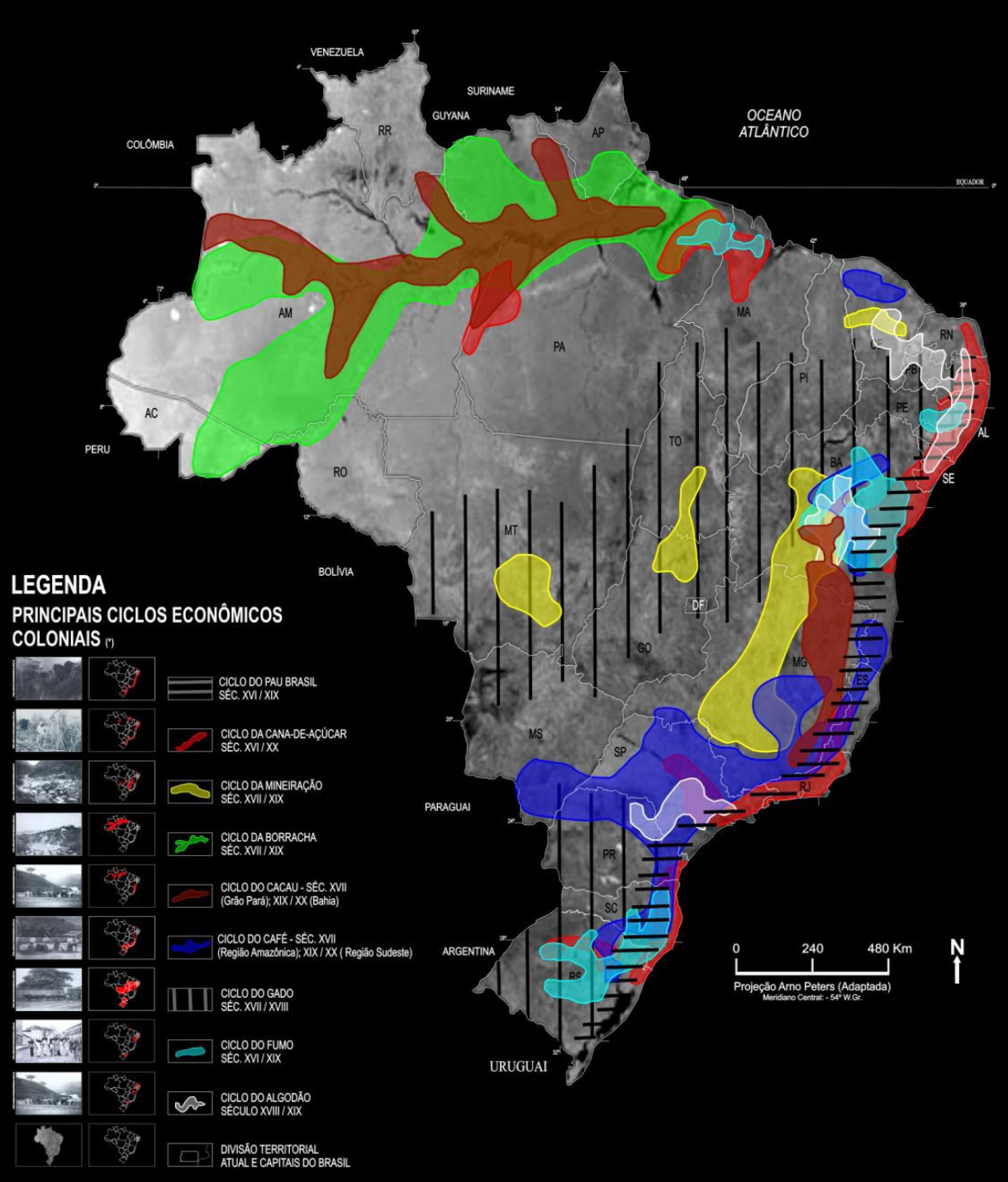

(") Fronteiras aproximados das áreas com atividades económicas desenvolvidas, principalmente, durante os séculos do sistema escravista no Brasil, que tinha como suporte base de produçäo, a força do trabalho e as tecnologias de refererncia a aficana.

Fonte: Rafael Sanzio Anjos (2010, p. 8). 
Figura 2 - Mapa das principais rotas do tráfico transatlântico

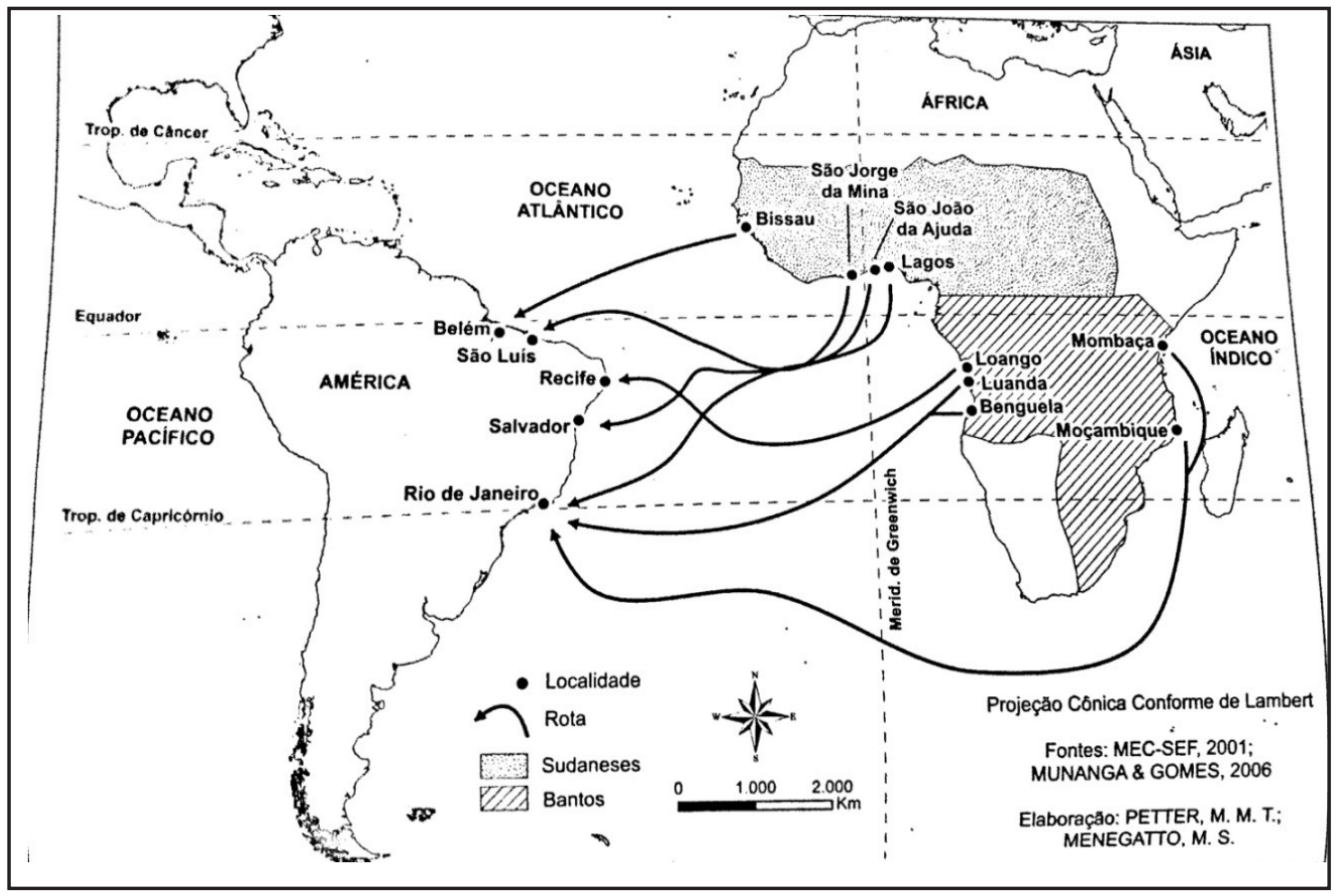

Fonte: Petter e Cunha (2015, p. 224).

Como resposta às necessidades prementes de comunicação entre os colonizadores e a população local, os pidgins de base portuguesa surgem, na África e, posteriormente, na Ásia, por imposição da língua de poder. Esse poder revelou-se, aliás, não só nos contatos internos locais com as populações nativas, mas, também, na comunicação necessária ao estabelecimento de trocas comerciais ou administrativas com outros europeus, pelo que o português se tornou língua franca em África e na Ásia, no decorrer o do século XVI (PINHEIRO, 2008).

A conquista do périplo africano pressupôs, portanto, o domínio cartográfico de uma territorialidade, o conhecimento de populações costeiras e suas línguas. No fim do século XV, os portugueses já haviam desenvolvido um interessante programa para o enfrentamento e o tratamento sistemático das dificuldades de comunicação e, mais tarde, das próprias línguas que iam sendo contatadas. Muitas das viagens a África não tinham como objetivo específico, ou único, o estabelecimento de relações comerciais ou a obtenção de escravos como força de 
trabalho, mas sim, conseguir intérpretes (em grande medida, também escravos), com vistas a garantir a comunicação na subsequente continuidade do empreendimento expansionista-colonial (PINHEIRO, 2008).

$\mathrm{Na}$ verdade, as comunidades multilíngues foram o cenário onde ocorreu a formação das línguas crioulas, uma vez que esses grupos tiveram pouco acesso ao modelo da língua portuguesa, uma vez que o quantitativo de falantes do português era inferior em seus grupos de convívio. Também pode ter ocorrido a perda parcial da funcionalidade das outras línguas maternas e a mistura entre línguas. De acordo com Pereira (1992, p. 268) "[...] estas condições ocorriam em zonas de concentração e isolamento das populações miscigenadas (como em Korlai, na Índia), longe das suas terras e culturas de origem, em particular, em plantações e em ilhas como as de Cabo Verde e S. Tomé, mas também nas fortificações costeiras edificadas pelos Portugueses nos séculos XV e XVI (como Cananor e Cochim)".

A interferência das culturas dos imigrantes e dos costumes das diferentes sociedades que aportaram no Brasil foi muito forte na língua portuguesa e na sociedade que se formava. Houve adaptações aos costumes, ao modo de vida, à maneira como as pessoas se comunicavam umas com as outras, para se fazerem compreender. Essas adaptações, que aperfeiçoaram a língua portuguesa falada no Brasil, identificam a sociedade brasileira de então. Era uma maneira de os brasileiros terem identidade, se estabelecerem como pertencentes à pátria brasileira e à cultura que nela se estabelecia.

Nesse contexto, um dado significativo apontado por Ribeiro (1995) é a tese de que os africanos seriam, eles mesmos, os principais difusores da língua portuguesa que eles aprendiam oralmente no convívio com seus colonizadores. Reprimidos pela política de separação étnica e linguística, eram obrigados a aceitar o português como mecanismo de contato, tanto com os demais escravos, quanto com os não-escravos. Conforme o autor, "[...] fazendo-o, se reumanizou [...] conseguindo dominar a nova língua, não só a refez, emprestando singularidade ao português do Brasil, mas também possibilitou sua difusão por todo o território" (RIBEIRO, 1995, p. 220).

De acordo com Botelho e Stolberg (2009, p. 263), soma-se ao exposto o fato:

[...] de existir grande número de africanos vivendo em terras brasileiras, o declínio da mão-de- obra indígena, especialmente nas regiões do Nordeste 
A toponímia de comunidades quilombolas do Centro-Oeste: relações entre língua, cultura e história nas formas de nomeação

e Sudeste, onde o português brasileiro já se configurava como língua predominante. Nas regiões do Sul, ainda com forte presença tupi e das línguas gerais dos jesuítas e dos bandeirantes, crescentes levas de imigrantes europeus, a abertura de novas frentes de exploração agropecuária e a consequente expulsão das populações autóctones trouxeram gradativamente, também para essa região, o predomínio do português. Durante o período dos quilombos, a identidade africana pôde se manifestar de forma una. Existem registros dessas comunidades de fugitivos dos martírios da escravidão que datam desde meados do século XVII e vem até a atualidade, quando as comunidades foram reconhecidas como descendentes diretos dos próprios quilombolas. Nesses locais, acredita-se que não eram faladas línguas africanas propriamente ditas, mas línguas gerais que mesclariam o português brasileiro em formação, o português europeu, línguas africanas variadas como fulfuldé, wolof, serei, temre, mande, kwa, ghe, ewen, gen, oj'a, fous, yoruba, nagô-ketu, nupe, igbo, ijó, tchadico, haussá, kanuri, somente para citar alguns, além das línguas indígenas. A proximidade com os futuros centros urbanos trazia sempre sua influência para dentro da comunidade e vice-versa; esses indivíduos exportavam sua produção linguística diária para as camadas da população com as quais tinha contato.

Na verdade, a consolidação da língua portuguesa em terras brasileiras ocorreu de fato por força das ações do Marquês de Pombal que, em 1758, obrigou oficialmente o uso da língua transplantada e proibiu a utilização da língua geral ${ }^{4}$ que garantia a comunicação entre os habitantes do território, além de ter expulsado os jesuítas, principais protetores da língua franca em terras brasileiras. Além disso, a vinda da Família Real para o Brasil, em 1808, também favoreceu a imigração de muitos portugueses para as terras brasileiras. A partir da independência política do Brasil (1822), as discussões em torno da questão da língua nacional tornaram-se mais presentes no parlamento brasileiro (LIMA; SALOMÃO, 2013).

O primeiro documento de que se tem registro escrito no Brasil acerca dos estudos das línguas africanas, conforme Petter (2004), é a gramática de 1697, a Arte da língua de Angola, oferecida à Virgem Nossa Senhora do Rosário Mãy e Nossa Senhora dos Meninos Pretos, escrita pelo Pe. Pedro Dias da Companhia de Jesus, na Oficina de Miguel Deslandes, impressor de Sua Majestade, com todas as licenças necessárias - Ano de 1697, 14,5 cm de dimensão e 48 páginas.

4 cf. Lagorio e Freire (2014) acerca da temática das línguas gerais no Brasil. 
Figura 3 - Primeiro documento escrito no Brasil sobre línguas africanas

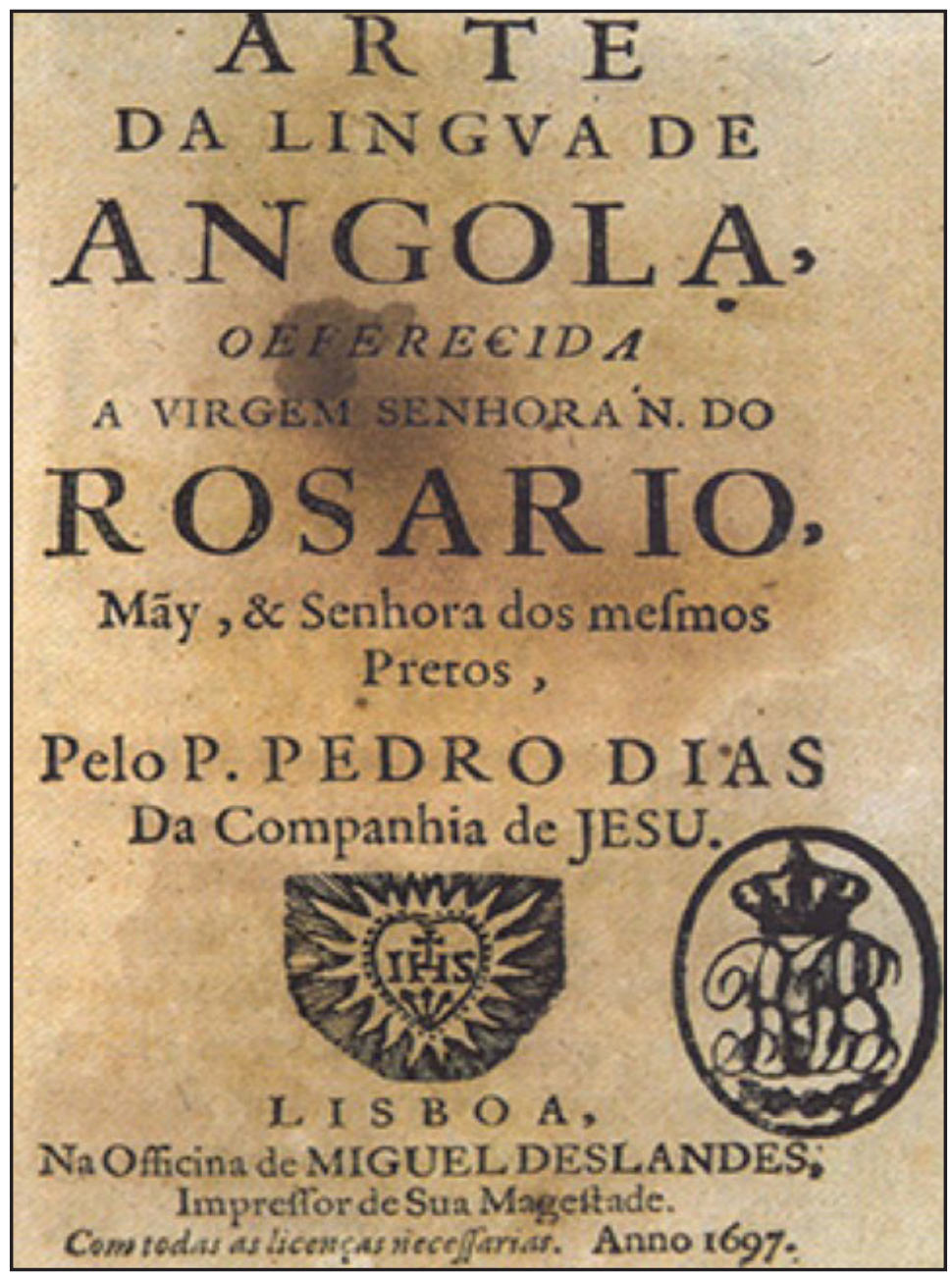

Fonte: Petter (2004, p. 23).

O autor desse trabalho era português, jesuíta, médico e jurista, que viveu a infância no Brasil e redigiu essa a gramática na Bahia para os jesuítas que iriam cuidar dos escravos originários da Angola. A importância dessa gramática é o testemunho do uso da língua africana quimbundo no território brasileiro. Ainda segundo Petter (2004), as contribuições da Linguística africana para as teorias linguísticas têm grande significância, uma vez que os dados originários da África 
colaboraram para corrigir teorias linguísticas eurocêntricas. Quando se trata dos africanismos na toponímia brasileira, têm-se os estudos das contribuições das línguas africanas mais faladas no país, como línguas da família Banto (quimbundo, kuicongo e umbundo) e as da família Kwa (lorubá).

Já ao se tratar, especificamente, sobre os estudos da toponímia africana a partir de Dick (1990), deve-se seguir algumas etapas metodológicas, inicialmente, com análises dos principais componentes étnicos imigrados, a classificação das línguas e o exame dos designativos, no que se refere à sua natureza semântica e às suas áreas de ocorrência. Dessa forma, por intermédio do mapa etnológico africano de Castro (2003) pode-se observar os possíveis grupos que se espalharam pelo Brasil: (B) Banto, jeje-mina (J), nagô-iorubá (N) e hauçá (H). Vejam-se os grupos mais detalhadamente no mapa a seguir.

Figura 4 - Esboço do mapa etnológico africano no Brasil

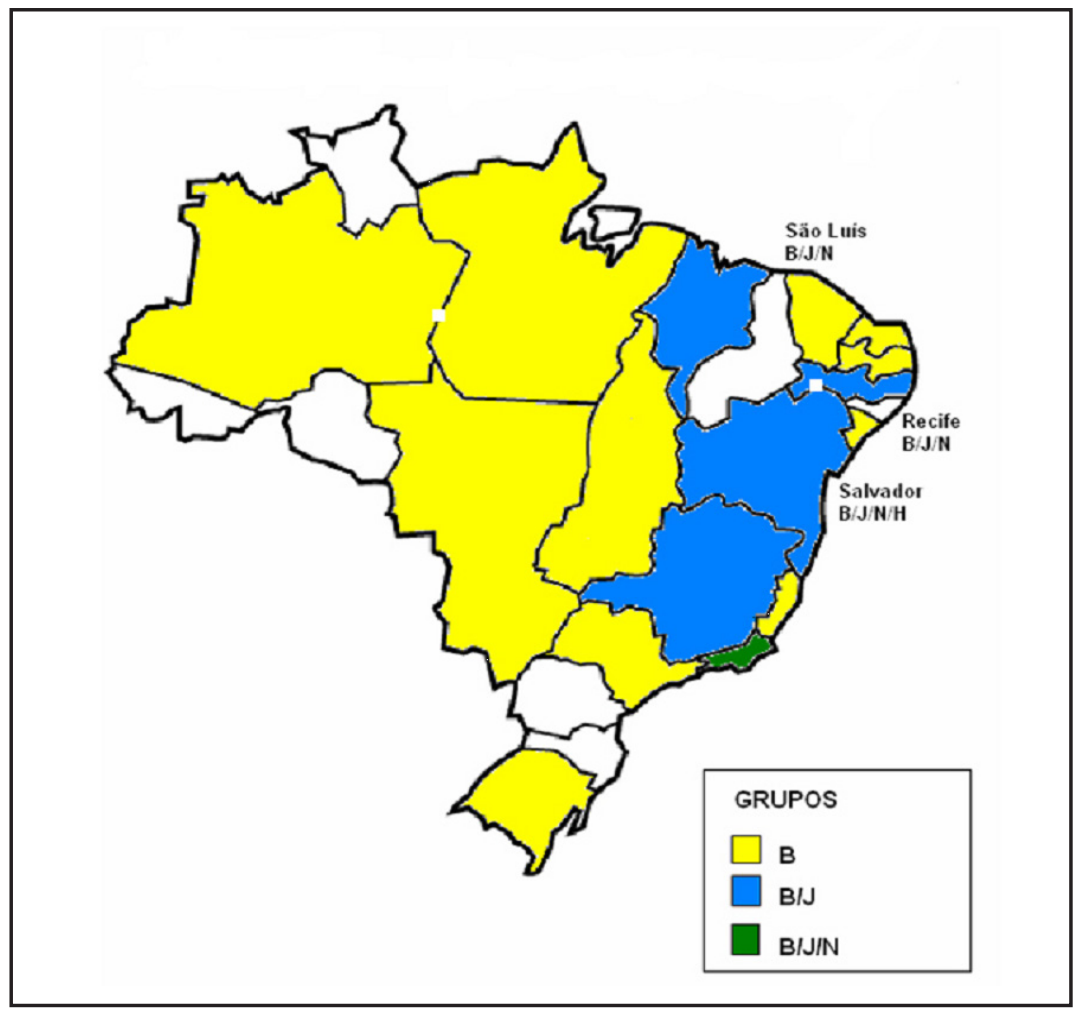

Fonte: Castro (2003, p. 25). 
Além desses procedimentos e reconhecimentos, Dick (1990) ainda considera importante valorizar os conhecimentos genéricos da problemática do negro no país:

Elemento alógeno, o africano que aqui se fixou, desde a segunda metade do século XVI, criou raízes no território e se tornou responsável pelo stock mestiço (mulatos e pardos) dos mais representativos no conjunto da população brasileira, se levarmos em conta as estatísticas elaboradas [...] Apesar de o tráfico negreiro ter tido como uma de suas causas a mão de obra barata, destinada, no Brasil ao trabalho agrícola nas plantações de cana-de-açúcar, fumo, cacau, café e algodão, dispersas pelas da Bahia, Sergipe, Pernambuco, Alagoas, Paraíba, Rio de Janeiro, São Paulo, Maranhão e Pará; os nas minerações das Gerais, Mato Grosso e, mesmo, no aproveitamento em serviços domésticos e/ou urbanos, não se pode considerar o negro como um elemento meramente "marginal" à sociedade brasileira. (DICK, 1990, p. 137-8).

Nos estudos toponímicos realizados no Brasil de modo geral, observa-se a pouca frequência de nomes de procedência africana, embora o número de negros tenha sido bastante significativo em todo o território. Essa "ausência" conduz à possibilidade de estudo de uma toponímia marcada ideologicamente pelo poder dominante da época, retratando o preconceito e discriminação dos povos africanos organizados em comunidades denominadas quilombolas.

Nesse contexto, não pode ser desconsiderado o fato de nos dois primeiros séculos do Brasil Colônia ser predominante no Brasil a população indígena, característica que vai se atenuando no decorrer do período colonial à medida que os mulatos descendentes do processo de miscigenação se tornaram a maioria absoluta da população brasileira, fenômeno que explica o fato de, nos séculos seguintes, mesmo com a chegada de novos contingentes de imigração europeia ao território brasileiro, ocorrer a predominância da população negra e, posteriormente, de afrodescendentes.

É fato que, durante o período colonial, foi estabelecido um estreito contato entre o português e as línguas africanas, além de os processos de pidginização e crioulização decorrentes desse período sempre marcarem as discussões daqueles que se ocupam da caracterização sócio-histórica do português do Brasil.

Motivados pela necessidade de afirmação de uma língua própria brasileira, no início do século XX, alguns teóricos, como Mendonça (1973), atribuíram a motivação de todas as características diferenciadoras do (PB) e (PE) às influências 
A toponímia de comunidades quilombolas do Centro-Oeste: relações entre língua, cultura e história nas formas de nomeação

africanas. Entretanto, não se pode negligenciar a ocorrência da transmissão irregular, sobrevindo possíveis crioulos e semicrioulos decorrentes do aprendizado "imperfeito" do português por falantes africanos.

Mattos e Silva (2004), por exemplo, em seu livro Ensaios para uma sociohistória do português brasileiro, trata no primeiro capítulo sobre "a emergência de uma língua nacional: trajetória convergente". Esse enunciado sintetiza a situação linguística do século XVIII, quando o português foi definido por Marquês de Pombal como língua da colônia e implementado o ensino leigo no Brasil, logo após a expulsão dos jesuítas. Essa atitude política mudou o curso histórico da chamada língua geral, que poderia ter sido a majoritária do país.

No entanto, para um estudo toponímico que considere as influências africanas na língua portuguesa no Brasil, torna-se necessário reconhecer a heterogeneidade e as diversidades do português em todos os níveis linguísticos. Não pode ser desconsiderado, por exemplo, que muitos aspectos fonéticos e fonológicos das variantes regionais e sociais da língua vernacular brasileira são atribuídos a interferências africanas. Também é notório que o léxico do português brasileiro foi bastante enriquecido com termos e expressões herdados das línguas africanas e, grande parte deles, são relacionados aos cultos afro-brasileiros.

Se por um lado o preconceito social e racial interferiu de forma significativa na língua brasileira, por outro, não há como negar a importância dos africanismos na formação do léxico do português do Brasil. Houaiss (1985, p. 71), por exemplo, argumenta que "a política sistemática seguida pelo Brasil para com os negros foi, desde o século XVI, glotocida, isto é, matadora de suas línguas". Essa assertiva remete a questões políticas que envolveram e desprestigiaram o contato do português com as línguas africanas.

Tratar das possibilidades das línguas africanas faladas no Brasil implica rememorar que a região denominada Senegâmbia ${ }^{5}$ abasteceu boa parte do

\footnotetext{
5 "A região da Senegâmbia, reúne as bacias dos rios Senegal e Gâmbia, é um pouco afastada do arco do Níger, na metade do caminho entre o Saara e a floresta" (BARRY, 2010, p. 313). "No interior, uma grande particularidade física da região da Senegâmbia é o vale do Senegal. Ela está margeada ao norte e no sul por baixas planícies costeiras e, no noroeste, no oeste e no sudoeste, por planaltos arenosos, dentre os quais o Hōdh (Hawd)" (ANDAH, 2010, p. 621). "A parte setentrional da Senegâmbia entre os rios Gâmbia e Senegal sofreu, por sua vez, uma profunda
} 
mercado colonial no século XVI, pois os portugueses deportaram membros de vários povos, como os manjacas, balantas, bijagos, mandigas, jalofo e, a partir do século XVI-XVIII, Angola e Congo abasteceram o mercado escravocrata brasileiro (MOTA, 2018, p. 10) (Figura 5).

Figura 5-Grande Senegâmbia

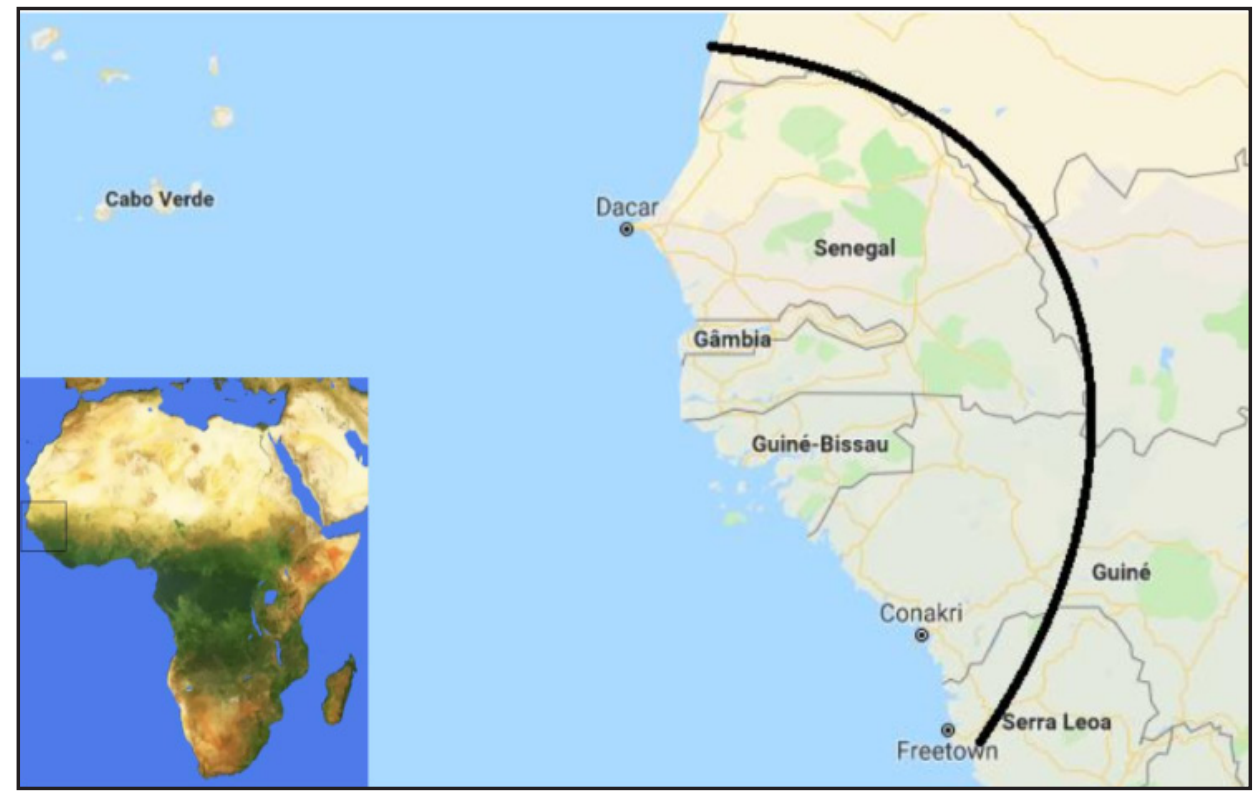

Fonte: Mota (2018, p. 10).

Silva Neto (1986), em sua obra Introdução ao estudo da língua portuguesa, traz documentos que asseguram o predomínio quase total da "língua geral" no Brasil, justificando que índios de diversas tribos, europeus e africanos utilizavam o sistema linguístico tupi na comunicação diária, o que justifica a dificuldade de realização de estudos sobre as especificidades das línguas africanas e indígenas no nível lexical, uma vez que os processos de aglutinação e formação espontânea desencadearam processos de hibridismo no português brasileiro, o qual pode até ser denominado como léxico afro-indígena-português, de certa forma aparentemente indissociável. Esse léxico faz-se representar, ainda que timidamente, na

e duradoura reorganização de seu mapa político, a partir da segunda metade do século XVII" (BARRY, 2010, p. 318). 
A toponímia de comunidades quilombolas do Centro-Oeste: relações entre língua, cultura e história nas formas de nomeação

toponímia brasileira, particularmente em determinadas regiões onde a línguas africanas tiveram maior representatividade.

\section{A TOPONÍMIA COMO ÁREA DE INVESTIGAÇÃO LINGUÍSTICA}

As pesquisas toponímicas tiveram início na França no início do século XIX. No Brasil, a obra pioneira O Tupi na Geografia Nacional de Teodoro Sampaio, de 1901, representa o marco inicial dos estudos de toponímia indígena no Brasil. A obra de Levy Cardoso (1961) e a de Carlos Drumond (1965) também representam contribuições significativas para o estudo da toponímia de base indígena no Brasil. Todavia, o grande impulso para as pesquisas toponímicas no Brasil ocorreu na década de 1980 com a defesa da Tese de Doutorado de Maria Vicentina do Amaral Dick, na Universidade de São Paulo, publicada em 1990 com o título "Motivação Toponímica e Realidade Brasileira". Dick construiu durante quase quatro décadas uma teoria toponímica que tem orientando as pesquisas nessa área no Brasil.

Neste estudo, o "pano de fundo" para a análise dos topônimos das comunidades quilombolas é a interdisciplinaridade, buscando em especial contribuições da Geografia, da História e da Antropologia, sem perder de vista, porém, a dimensão linguística dos estudos dos nomes de lugares foco principal deste trabalho. Uma problemática para o estudo da toponímia de base indígena, por exemplo, é a carência de estudos profundos sobre a língua Tupi e os equívocos na descrição de nomes indígenas não tupis e nomes de origem africana. As orientações de Drumond (1965), ao considerar os elementos extralinguísticos como causa denominativa de um determinado lugar e ao recuperar a perspectiva do denominador, torna perceptível os fatores de ordem histórica, social e cognitiva na representação do espaço.

O universo experiencial do ser humano, o meio que o envolve e suas práticas culturais refletem-se no seu modo de perceber a realidade e de nomear os espaços geográficos. Os estudos dos topônimos permitem mapear uma determinada região e perceber recortes da cultura da história do grupo que ali habita, uma vez que os nomes de lugares atuam como ícones do universo sociocultural da comunidade, no caso deste estudo, das comunidades quilombolas.

Dick (1992) propôs uma divisão taxonômica de natureza de ordem física e de cunho antropocultural. A classificação se pauta na análise do repertório dos 
nomes presentes na toponímia brasileira, revelando os traços da caracterização brasileira de uma toponímia recente, que fora trazida pelos europeus (toponímia portuguesa), acrescida de uma variedade de nomes de origem indígena e africana. Essa proposta de Dick (1992) tenta evitar o caráter especulativo e os "achismos" na investigação dos fatos ao propor uma terminologia de caráter científico.

No que se refere às motivações, Dick (1999) pondera que as circunstâncias socioculturais revelam a realidade que integra o denominador e pode auxiliar no conhecimento das razões da nomeação naquele espaço de tempo.

\section{A TOPONÍMIA COMO MARCAÇÃO IDEOLÓGICA DAS COMUNIDADES QUILOMBOLAS NO CENTRO-OESTE}

A visão do denominador em determinado tempo e espaço torna perceptível a tese de que o nome se entrelaça ao histórico da vida de determinado grupo, motivo pelo qual a atribuição dos nomes das comunidades quilombolas se materializa por intermédio da soma dos fatores étnicos, socioculturais e ideológicos. Neste artigo, em específico, trata-se de topônimos ligados à história que, de acordo com Dick (1998), seriam também condutores de ideologias, uma vez que o ato de nomear mesmo sem contemplar questões geográficas ou evento histórico, por si só, pode ser capaz de refletir as intenções de quem o nomeia.

No texto de Dauzat (1926-1972) encontram-se exemplos de cidades gaulesas que tiveram seus nomes celtas substituídos por nomes latinos, o que reflete o domínio romano e suas ideologias. Também no mesmo texto encontram-se os nomes romanos de divindades e imperadores que na Idade Média que foram substituídos por nomes religiosos do Cristianismo e, mais tarde, por nomes de reis do Ocidente.

Nessa perspectiva, retoma-se Dick (1998, p. 4) que pondera sobre os nomes e as marcações ideológicas que destacam a relação entre dominante/dominado, a supremacia do mando e da sujeição, mesmo que esse poder não seja constituído por transmissão hereditária. Transferindo o ponto de vista de Dick (1998) para o exame dos dados examinados no âmbito deste estudo, notam-se traços ideológicos ora mais evidentes, ora mais implícitos nos nomes das comunidades quilombolas analisados, à medida que podem revelar muito da pressão social e coerção do sistema imposto aos seus membros. 
Assim, a organização coletiva conduziu os relatos dos indivíduos em uma rede semiótica de tensões e conflitos que se reflete na nomeação das comunidades. No caso, a carga "afetiva" do topônimo não é inofensiva, uma vez que a designação de um dado lugar por um determinado nome reflete a identidade de um grupo. Assim, ao tratar a nomeação do espaço territorial ficam, ainda mais nítidas, relações de sobrevivência, domínio e subsistência.

Por intermédio da observação de questões ideológicas no âmbito dos estudos toponímicos pode-se inferir possível uma dicotomia entre a ciência como a estrutura analítica e a ideologia como conjunto de crenças e valores. "Enquanto a ciência é a dimensão de diagnóstico, de crítica da cultura, a ideologia é a dimensão justificadora, apologética - refere-se à parcela da cultura que se preocupa ativamente com o estabelecimento e a defesa dos padrões de crença e valor" (GEERTZ, 2011, p. 133). Os estudos toponímicos permitem, pois, uma visão dialética entre dominante/dominado, entre poder e sujeição. O exame dos nomes das comunidades quilombolas aponta para a possibilidade de serem considerados também questionamentos e ideários que envolveram a história e cultura dessas comunidades.

Como já assinalado, o corpus analisado neste trabalho foi constituído pelos nomes das 131 comunidades quilombolas localizadas na região Centro-Oeste, certificadas pelo IBGE, até 2016. A análise apresenta uma visualização dos dados segundo o Estado, traçando-se uma comparação entre os dados no que diz respeito a origem etimológica dos topônimos. Na sequência, apresenta-se um quadro geral com a distribuição dos dados toponímicos segundo a taxionomia (DICK, 1992) e apontam-se possíveis questões ideológicas e históricas relacionadas aos dados examinados. A Figura 6, na sequência, traz a distribuição dos dados segundo as unidades da Federação. 
Figura 6 - Mapa de localização das comunidades quilombolas na Região Centro-Oeste (GO, MS, MT)

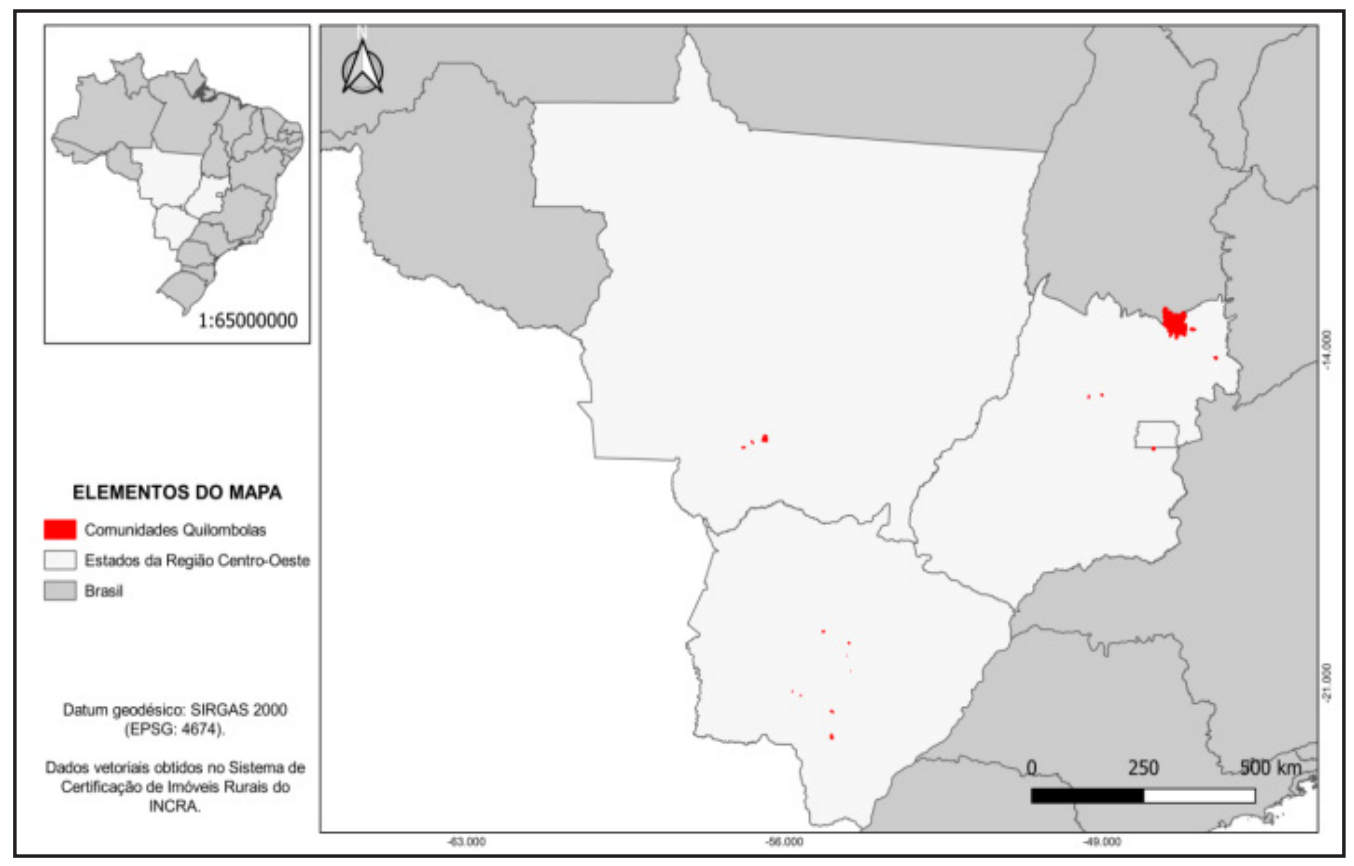

Fonte: Elaboração das autoras.

Mato Grosso reúne o maior número de comunidades quilombolas do Centro-Oeste (78), seguido de Goiás (32), onde se encontra a maior extensão quilombola territorial do Brasil (comunidade Kalunga) e Mato Grosso do Sul (21). Ao ser considerada a língua de origem dos nomes em estudo, em especial a busca de vestígios de línguas africanas na nomeação das comunidades quilombolas, é importante levar em conta a dimensão mítico da língua para o africano, o que, de certa forma, pode ter sido transmitido para os grupos étnicos quilombolas, mesmo que esses traços culturais não estejam evidenciados no nome atribuído à comunidade. O gráfico que segue informa a distribuição dos 131 topônimos analisados quanto à língua de origem. 
Gráfico 1 - Distribuição dos topônimos das comunidades quilombolas por Estado da região Centro-Oeste, segundo a língua de origem dos nomes

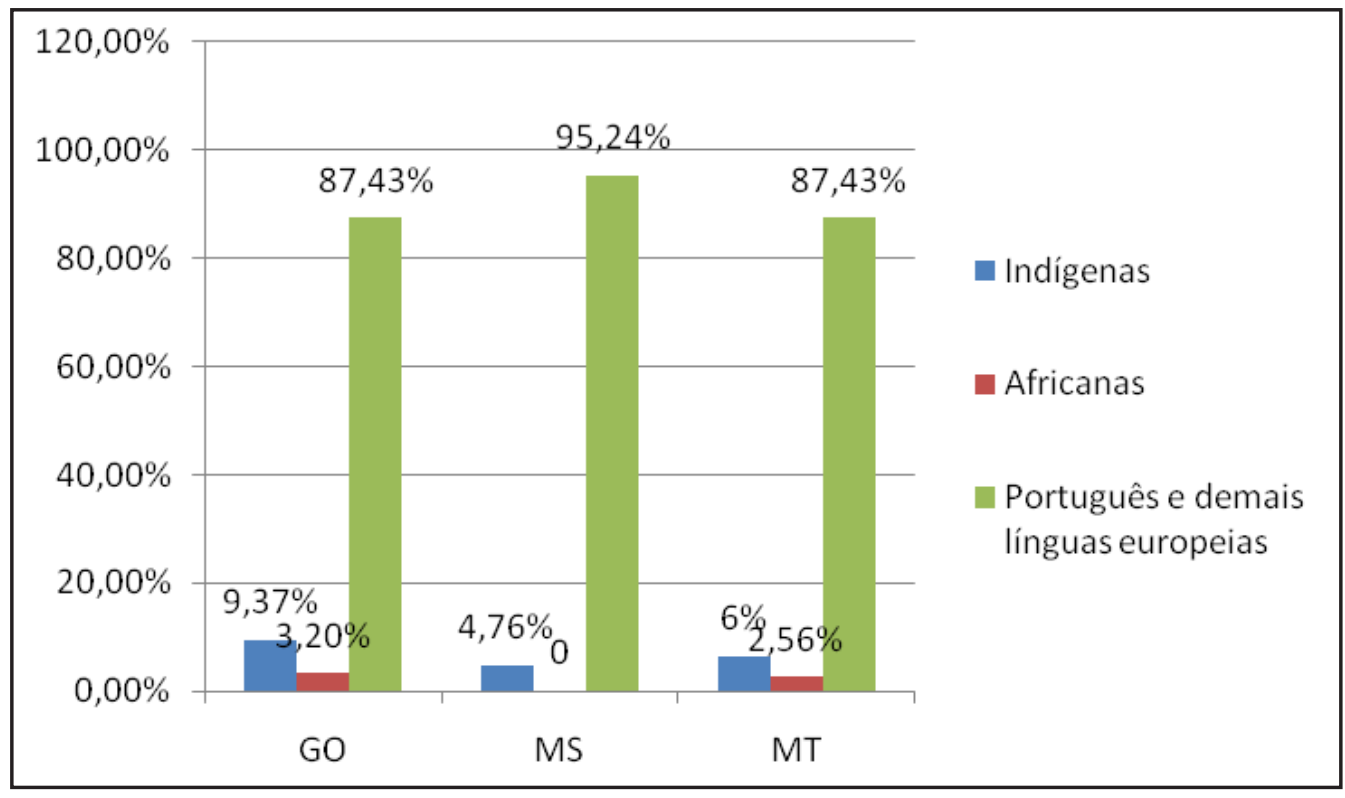

Fonte: Elaboração das autoras.

Os dados demonstram que o português, a língua do colonizador, prevalece com grande margem de ocorrência em relação às demais línguas, no caso, a Tupi e as línguas africanas que alçaram percentuais mínimos. No Mato Grosso, devido ao quantitativo de comunidades, percebe-se a maior ocorrência de topônimos de base Tupi e africana, como: Y-mbé (tupi; planta rasteira, trepadeira), segundo Sampaio (1928, p. 222); Monjolo (africano; quimb./quic. mansilu > mansulo 'espécie de almofariz’ usado para pilar milho e descascar café), conforme Castro (2001, p. 288).

Em Mato Grosso do Sul não houve registro de topônimo de base africana na nomeação das comunidades. Foi identificado um pequeno percentual de nomes indígenas e a grande maioria de topônimos de base portuguesa. Entende-se que isso não interfere na legitimação dos grupos, uma vez que o denominador reflete sua ideologia por intermédio do ato de nomeação, nesses casos, houve a valorização da língua de prestígio e domínio, seja pelas autoridades, seja pelos moradores, já que não há registros sobre o responsável pela nomeação. Um indicador que se destaca na nomeação de comunidades do Mato Grosso do Sul é a valorização 
de nomes de famílias na toponímia quilombola, o que provavelmente pode ser um indício da presença de questões históricas relacionadas ao negro escravizado, que era obrigado a adotar o nome e sobrenome do seu "senhor". Essa prática é apontada por Palma e Truzzi (2018, p. 4):

A apropriação de um nome, para além do processo de individualização da identidade que ele representa, traz consigo a questão da inserção do indivíduo nas estruturas jurídicas e administrativas do Estado. A assimilação de um nome designa, de um lado, a existência de um ser humano como radicalmente singular e, de outro, as múltiplas ordens sociais que the conferem sentido. Nas burocracias do Estado, um nome delimita, de modo geral, a singularidade da pessoa no tempo (as múltiplas possibilidades de filiação e de linhagens, por exemplo) e no espaço (lugar de nascimento, terras familiares etc.). No caso específico dos cativos que desembarcaram em terras brasileiras, essa singularização não era assim tão clara e evidente. $\mathrm{O}$ ato do batismo fixava uma espécie de protoestado civil nos africanos escravizados. A simples inscrição de um nome em um documento, como é o caso dos certificados de batismo, conferia ao seu detentor, contudo, certos potenciais de poder que não podem ser negligenciados. Tal potencialidade, por sua vez, foi a responsável pela produção de estatutos jurídicos ambíguos em relação aos cativos em diversos registros. Embora a própria palavra escravo traga implícita a ideia de pessoa portadora de nenhum gênero de direito, o simples registro de batismo oferecia aos cativos a possibilidade de ter um nome, isto é, um contorno de individualidade. Não foram poucas, porém, as investidas que escrivães, notários, tabeliões, padres e fazendeiros fizeram para tentar amenizar ao máximo essa individualidade. Quanto aos cativos, após receberem apenas uma denominação genérica, alguns introduziam, com o tempo, nomes compostos e designações que remetiam às suas origens. $O$ tráfico atlântico, por exemplo, criou determinadas categorias para classificar a procedência dos cativos africanos. As chamadas "nações" foram as mais utilizadas. Elas consistiam em nomes de macrorregiões, portos ou reinos onde era praticado o comércio de cativos. Esses termos não faziam sentido nas identificações dos próprios escravos, porém não é incomum encontrar, nos registros oficiais, nomes de cativos seguidos de termos como "mina", "benguela", "congo" e "angola". Talvez porque esse tipo de designação não pudesse ser introduzido oficialmente, sendo mais uma espécie de "rótulo de mercado" do que uma identificação comunitária.

Esses fatores ligados à identidade se manifestam por meio da presença de nomes de famílias na nomeação de comunidades quilombolas de Mato Grosso do Sul, incluindo o próprio termo "família" na composição do nome do lugar, o 
que pode refletir traços de ideologia e o poder, de um lado o domínio e as marcas da escravidão e, de outro, uma forma de identificação com os não negros e uma manifestação de "liberdade" e de portador de uma identidade. Nesse particular, é interessante rememorar o conceito de família para o africano, uma vez que no território brasileiro foi frequente a formação de "famílias escravas" que foram estabelecidas pelos rituais, mesmo sem traços consanguíneos, o que, por extensão, pode atravessar os limites da condição de escravo e de pessoas livres.

A atribuição, às comunidades quilombolas, de nomes como Família Bispo, Família Quintino, Família Jarcem pode traduzir um viés e um olhar ideológico de marcador de identidade, embora esses topônimos não sejam formados por étimos de origem africana, podendo transparecer um marcador ideológico marcado pelo conceito e imagem da família que transcendem as relações consanguíneas e materializam a história da comunidade.

Por fim, Goiás abriga o maior território quilombola do Brasil, denominado Kalunga: "calunga (kimb.) (LS), o mar; o fundo da terra; o abismo; a divindade poderosa; seus símbolos" (CASTRO, 2001, p. 192). Nesse Estado, há também a ocorrência de topônimos de origem indígena como em Baco Pari Bacupari: "design. comum a árvores do gên. Garcínia (que inclui o gên. Rheedia), da fam. das clusiáceas, cujos frutos são ger. comestíveis" (CUNHA, 2010, p. 75).

Quando se considera a história do negro e da formação dos quilombos no período colonial, faz-se necessário observar que algumas regiões esses grupos abrigavam indígenas e até mesmo brancos pobres ou criminosos na condição de fuga, o que pode explicar a presença de nomes indígenas na nomeação das comunidades em estudo.

Outro aspecto a ser considerado é o enquadramento dos topônimos ao modelo taxionômico de Dick (1992) que considera a motivação dos nomes expressa pela etimologia do item lexical investido de função toponímica. Ilustrando com dados de algumas taxes de natureza antropocultural, tem-se ocorrências de sociotopônimos (Chácara do Buriti; Retiro; Rodeio); geomorfotopônimos (Morro Redondo; Furnas da Boa Sorte); fitotopônimos (Capão Novo; Manga); hagiotopônimos (Nossa Senhora Aparecida; São Gonçalo); antropotopônimos (Antônio Borges; Tomás Carneiro); animotopônimos (Boa Nova; Bela Cor); hodotopônimos (Passagem de Carro), dentre outros. 
Como se pode observar, na região Centro-Oeste a taxe mais produtiva na nomeação das comunidades quilombolas foram os sociotopônimos, nomes que remetem a atividades profissionais e a pontos de encontro, pontos esses que podem ser relacionados à própria situação histórica do negro no Brasil no período da escravidão, uma vez que, mesmo após a Lei Áurea, muitos ainda permaneciam na condição de escravos. Pode-se ainda considerar que a sociedade pós abolição ainda via/vê o negro na posição de objeto pertencente ao seu senhor, motivo pelo qual pode-se acreditar que comunidades receberam os nomes da família de "donos" a quem descendentes africanos pertenceram, mas também pode remeter ao conceito de "família escrava" que, embora não possua laços de parentesco, pertencem a rituais africanos.

Tratando-se dos hagiotopônimos, encontrados também em Dick (2008, p. 226), são nomes de lugares que remetem ao sagrado, à busca da proteção divina, além de remeter à questão do sincretismo religioso como uma marca de resistência, uma vez que, no Brasil, os negros escravizados, como tiveram seus cultos proibidos, como forma de resistência, relacionavam os santos do Catolicismo às entidades do Candomblé, fenômeno denominado como sincretismo religioso. A seguir, o Quadro 2, reúne hagiotopônimos que nomeiam as comunidades no Centro-Oeste e sua relação com as entidades do Candomblé.

Quadro 2 - Hagiotoponímia das comunidades quilombolas do Centro-Oeste e a questão do sincretismo religioso

\begin{tabular}{|c|c|}
\hline Hagiotopônimo & Entidade africana \\
\hline Nossa Senhora Aparecida $^{6}$ & Oxum $^{7}$ no Candomblé \\
\hline Santo Antônio $^{8}$ & Exú \\
\hline
\end{tabular}

\footnotetext{
6 Na década de 30 do século XX em busca da identidade nacional, o governo de Getúlio Vargas estabeleceu Nossa Senhora Aparecida como a Padroeira do Brasil. Maria apareceu no Brasil na forma de uma imagem negra, na época em que a escravidão no país estava em alta. Maria foi proclamada Nossa Senhora da Conceição Aparecida, Rainha do Brasil, em 16 de julho de 1930 pelo Papa Pio XI. O Brasil rende-se ao amor incondicional da "Mãe negra" no dia 12 de outubro, data que marcou, em 1980, a proclamação de feriado e consagração do Santuário Nacional de Aparecida pelo Papa João Paulo II.

7 "O seu Orixá correspondente no sincretismo afro-católico".

8 Há relações estreitas com Exu devido ao dom da oratória; também aos milagres a favor do casamento praticados, tanto por Santo Antônio quanto por Exu.
} 
A toponímia de comunidades quilombolas do Centro-Oeste: relações entre língua, cultura e história nas formas de nomeação

\begin{tabular}{|c|c|}
\hline Hagiotopônimo & Entidade africana \\
\hline São João Batista / São Gerônimo & Xang $^{9}$ \\
\hline Santa Tereza & \\
\hline São Gonçalo & Orixá Oxossi \\
\hline S. Benedito & \\
\hline
\end{tabular}

Fonte: Elaboração das autoras.

Elementos da cultura africana que por muitos anos permaneceram na oralidade. Assim, há entre o grupo a crença do poder da palavra nas diversas formas de rituais, nos quais é transmitido o poder da ação. Essa condição faz jus ao já dito defendido por Biderman (1998, p. 82), quando argumenta acerca da dimensão mágico-religiosa da palavra. Nesse sentido, nos dados examinados, percebe-se que a toponímia quilombola evidencia também índices de questões políticas, religiosas, ideológicas relacionadas à sócio história do Brasil.

\section{CONSIDERAÇÕES FINAIS}

Revisitar a toponímiaque nomeia comunidades quilombolas implicou a reflexão sobre marcas do período colonial; a pluralidade de culturas e as raízes históricas, espelhadas na forma de nomeação dessas comunidades que deixam transparecer a visão de mundo do denominador e sua ideologia impressas na toponímia, independente da identidade do denominador, seja ele o próprio negro ou não.

Apesar da importância da colonização africana no Brasil, durante um longo período da história na sociedade brasileira ocorreu o ocultamento da influência africana na cultura e na língua, sendo tal posicionamento justificado por intermédio da imagem de unidade e conservadorismo de alguns teóricos, que abordavam uma visão de superioridade cultural do colonizador branco, além das limitadas concepções sobre línguas crioulas, vistas como simplificação ou deturpação do português no Brasil.

Há pouca representatividade do negro e das suas línguas na nomeação das

9 Xangô é considerado o Orixá da justiça e da sabedoria. Disponível em: http://www.girasdeumbanda.com.br/orixas/.

${ }^{10}$ Os escravos africanos se identificavam com sua pele negra e passaram a admirá-lo. Por isso, também é conhecido como o protetor dos negros. 
comunidades quilombolas, o que aponta pela questões ideológicas que podem conduzir o estudioso para uma possível interpretação que considere a posição do negro no processo de nomeação, o que interfere nas escolhas lexicais que, por sua vez, podem evocar qualquer tipo de parentesco a grosso modo (família, tio, avó, mãe) termos que na cultura africana extrapola os laços sanguíneos e podem evocar o sagrado e o divino, mesmo que não estejam registrados nas línguas africanas.

No que concerne à hagiotoponímia quilombola notam-se marcas do sincretismo, fenômeno que não se restringe às populações africanas, à medida que se estende ao fenômeno do hibridismo cultural em que se mesclam ritos europeus, africanos e indígenas, traço observado em graus distintos na toponímia quilombola em geral. A continuidade da pesquisa, a partir dos dados de outras regiões, poderá confirmar ou refutar as tendências identificadas no recorte de nomes aqui analisados.

\section{REFERÊNCIAS}

ANDAH, Bassey Wai. Os povos da Guiné superior (entre a Costa do Marfim e a Casamância). In: FASI, Mohammed El. História geral da África: África do século VII ao XI. Brasília: UNESCO, 2010. p. 618-52. v. 3.

ANJOS, Rafael Sanzio. A geografia do Brasil africano, o congo e a Bélgica. Revista Eletrônica Tempo - Técnica - Território, Brasília, v. 1, n. 3, p. 8-10, 2010.

BARRY, Boubacar. A Senegâmbia do século XVI ao XVIII: a evolução dos Wolofes, dos Sereres e dos Tucolores. In: BOGOT, Bethwell Allan. História geral da África: África do século XVI ao XVIII. Brasília: UNESCO, 2010. p. 313-56. v. 5.

BIDERMAN, Maria Tereza Camargo. Dimensões da palavra. Filologia e Linguística Portuguesa, São Paulo, v. 1, n. 2, p. 81-118, 1998.

BOTELHO, André; STOLBERG, Daiane. As origens do português brasileiro. Eletras, v. 18, n. 18, p. 12-6, jul. 2009.

CAPUCHO, Maria Filomena. íngua, expressões linguísticas e diversidade cultural. Portugal: percursos de interculturalidade, Lisboa, v. 3, p. 253-98, 2008.

CARDOSO, Armando Levy. Toponímia brasílica: índices alfabéticos de autores, nomes de lugares e tribos e de matérias. Rio de Janeiro: Biblioteca do Exército, 1961. (Coleção 
A toponímia de comunidades quilombolas do Centro-Oeste: relações entre língua, cultura e história nas formas de nomeação

General Benício).

CASTRO, Yeda Pessoa. Falares africanos na Bahia: um vocabulário afro-brasileiro. Salvador: Editora Topbooks, 2001.

CASTRO, Yeda Pessoa. A diversidade das línguas africanas e as relações linguísticas BrasilÁfrica. Salvador: UNEB, 2003.

CHILDS, George Tucker. Uma introdução às línguas africanas. Amsterdã: Publicação John Benjamins, 2003.

CUNHA, Antônio Geraldo. Dicionário etimológico. 4. ed. Rio de Janeiro: Lexikon, 2010.

DAUZAT, Albert. Les noms de lieux. Paris: Librairie Delagrave, 1926.

DICK, Maria Vicentina de Paula do Amaral. Etnia e etnicidade: um novo modo de nomear. In: ISQUERDO, Aparecida Negri; FINATTO, Maria José B. (Org.). As ciências do léxico: lexicologia, lexicografia, terminologia. Campo Grande: Editora UFMS, 2008. p. 231-15. v. 4.

DICK, Maria Vicentina de Paula do Amaral. Métodos e questões terminológicas na onomástica. Estudo de caso: o Atlas Toponímico do estado de São Paulo. Investigações Linguística e Teoria Literária, Recife, v. 9, n. 1, p. 119-48, 1999.

DICK, Maria Vicentina de Paula do Amaral. Os nomes como marcadores ideológicos. Acta Semiótica et Lingvistica, São Paulo, v. 7, n. 1, p. 97-122, 1998.

DICK, Maria Vicentina de Paula do Amaral. Toponímia e antroponímia no Brasil. São Paulo: USP/FFLCH, 1992. (Coletânea de Estudos).

DICK, Maria Vicentina de Paula do Amaral. A motivação toponímica e a realidade brasileira. São Paulo: Edições Arquivo do Estado de São Paulo, 1990.

DRUMOND, Carlos. Contribuição do bororo à toponímia brasílica. São Paulo: Instituto de Estudos Brasileiros/USP, 1965.

GEERTZ, C. Nova luz sobre a antropologia. Rio de Janeiro: Jorge Zahar, 2011.

HOUAISS, Antônio. O português do Brasil: pequena enciclopédia da cultura brasileira. Rio de Janeiro: UNIBRADE, 1985.

LAGORIO, Consuelo Alfaro; FREIRE, José R. Bessa. Aryon Rodrigues e as línguas gerais na historiografia linguística. DELTA, São Paulo, v. 30, n. Especial, p. 571-89, 2014. Disponível em: https://www.scielo.br/pdf/delta/v30nspe/0102-4450-delta- 
30-spe-0571.pdf. Acesso em: 24 out. 2020.

LIMA, Ana Laura Araújo; SALOMÃO, Jacilene Marques. Do português europeu ao português brasileiro: origens e formação histórica da língua portuguesa. Revista Pandora Brasil, São Paulo, v. 1, n. 52, p. 102-12, 2013.

MATTOS E SILVA, Rosa Virgínia. Ensaios para uma sociohistória do português brasileiro. São Paulo: Parábola Editorial, 2004.

MENDONÇA, Renato. A influência africana no português do Brasil. 4. ed. Rio de Janeiro: Civilização Brasileira, 1973.

MOTA, Thiago Henrique. História atlântica da islamização na África Ocidental: Senegâmbia, séculos XVI e XVII. 2018. 373 f. Tese (Doutorado em História) Universidade Federal de Minas Gerais, Belo Horizonte, MG, 2018.

MUSSA, Alberto. O papel das línguas africanas na história do português do Brasil. 1991. 280 f. Dissertação (Mestrado em Linguística) - Universidade Federal do Rio de Janeiro, Rio de Janeiro, RJ, 1991.

PALMA, Rogerio; TRUZZI, Oswaldo. Renomear para recomeçar: lógicas onomásticas no pós-abolição. Revista de Ciências Sociais, Rio de Janeiro, v. 61, n. 2, p. 311-40, 2018

PEREIRA, Dulce. Crioulos de base portuguesa. In: FERRONHA, André Luís et al. Atlas da língua portuguesa. Lisboa: União Latina, 1992. p. 120-5.

PETTER, Margarida; CUNHA, Ana. Línguas africanas no Brasil. In: PETTER, Margarida (Org.). Introdução à linguística africana: São Paulo: Contexto, 2015.

PETTER, Margarida. Linguagem, língua, linguística. In: FIORIN, Jose Luiz (Org.). Introdução à linguística I: objetos teóricos. 4. ed. São Paulo: Contexto, 2004.

PRANDI, Reginaldo. De africano a afro-brasileiro: etnia, identidade, religião. Revista USP, São Paulo, v. 1, n. 46, p. 52-65, 2000.

PINHEIRO, Cláudio. pereirLíngua e conquista: formação de intérpretes e políticas imperiais portuguesas de comunicação em Ásia nos alvores da modernidade. In: LIMA, I. S.; CARMO, C. (Org.). História social da língua nacional. Rio de Janeiro: Edições Casa de Rui Barbosa, 2008.

RIBEIRO, Darcy. O povo brasileiro: a formação e o sentido do Brasil. São Paulo: Cia das 
A toponímia de comunidades quilombolas do Centro-Oeste: relações entre língua, cultura e história nas formas de nomeação

Letras, 1995.

SILVA NETO, Serafim. Introdução ao estudo da língua portuguesa no Brasil. 3. ed. Rio de Janeiro: Presença, 1986.

\section{Sobre as autoras:}

Nagila Kelli Prado Sana Utinói: Doutoranda em Letras pela Universidade Federal de Mato Grosso do Sul (UFMS). Mestre em Letras pela Universidade Estadual de Mato Grosso do Sul (UEMS). Licenciada em Letras Português/ Inglês e suas respectivas literaturas pela UEMS. Professora efetiva na Secretária do Estado de Mato Grosso do Sul. E-mail: nagilakelli@gmail.com, ORCID: https://orcid.org/0000-0002-3146-3986

Aparecida Negri Isquerdo: Doutora em Letras pela Universidade Estadual Paulista "Júlio de Mesquita Filho" (UNESP). Graduada em Letras pela Universidade Estadual de Mato Grosso (UFMT). Docente aposentada pela Universidade Federal de Mato Grosso do Sul (UFMS). Atualmente é docente permanente e pesquisadora visitando na UFMS. E-mail: aparecida.isqueiro@gmail.com, ORCID: https://orcid.org/0000-0003-1129-5775

Recebido em: 20/11/2020

Aprovado para publicação em: 16/12/2020 
